\title{
STRATEGI PEMASARAN DAN PENGEMBANGAN TEPUNG CASSAVA PADA AGROINDUSTRI UD. NULA ABADI DI KABUPATEN BONDOWOSO
}

\author{
Achmad Budi Santoso ${ }^{1}$ dan Joni Murti Mulyo Aji ${ }^{2}$ \\ ${ }^{1}$ Mahasiswa, Program Studi Agribisnis Fakultas Pertanian Universitas Jember \\ ${ }^{2}$ Dosen, Program Studi Agribisnis Fakultas Pertanian Universitas Jember \\ email: Achmadsantosa50@Gmail.com
}

\begin{abstract}
Cassava flour is one of the derivative products obtained from cassava processing. Cassava flour is different from tapioca because of the soaking process and has higher nutritional value. This research aims to analyze: 1) Channels and marketing efficiency of cassava flour, 2) Revenue and cost efficiency of cassava flour production and 3) Strategy recommendation for developing cassava flour production and marketing. The research area was determined purposively method with the consideration that UD. Nula Abadi is new agroindustry with innovative products that are still not widely known by people in Bondowoso Regency. The sample of the producer was determined using purposive sampling and snowball sampling, especially for the marketing agency. Data were collected by interview, observation, and documentation. Data analysis used in this research includes marketing margin, share, and efficiency to answer the first problem and analysis of income as well as the $R / C$ ratio to answer the second problem. The analysis of marketing channels and SWOT is done descriptively to answer the third problem. The results showed that 1) marketing channel of cassava flour on UD. Nula Abadi consists of 3 marketing channels and channel II (Manufacturer - Large trader - Consumer household/agroindustry) is the most efficient. 2) Total revenue of cassava flour Rp. 6.250.000,00 with total production costs of $R p$. 3.525.458,33, so that the amount of income is $R p .2 .724 .541,67$. The value of production cost efficiency $(R / C$ ratio) obtained is $1,17.3)$ The competitive relative position of cassava flour agroindustry is located in the field of White Area or potentially strong field, meaning that the agroindustry can use its competence to exploit the prospective opportunity.
\end{abstract}

Keywords: Cassava Flour, Marketing Efficiency, R/C ratio, SWOT.

\section{PENDAHULUAN}

Pengembangan aneka produk yang berbasis umbi-umbian dapat menunjang peningkatan kesejahteraan masyarakat, disamping meningkatkan nilai sosial komoditas (Sukesi, 2010). Umbi-umbian belum mendapatkan perhatian dari masyarakat bahkan peluang pasarnya masih relatif kecil karena kegunaannya belum banyak diketahui, oleh karena itu diperlukan sosialisasi untuk menarik petani untuk meningkatkan nilai tambah dan daya saing produk olahan umbi-umbian sebagai produk substitusi. Hal ini akan berimplikasi terhadap terpenuhinya kebutuhan pangan lokal, peningkatan pertumbuhan ekonomi melalui peningkatan pendapatan petani serta akan berpengaruh terhadap respon petani dalam membudidayakan tanaman umbi-umbian
(Hanastiti, 2013).

Salah satu tanaman pangan di Indonesia yang mempunyai potensi cukup besar untuk dikembangkan sebagai bahan pangan alternatif adalah singkong. Melalui Peraturan Menteri Pertanian No. 18/Permentan/OT.140/2/2010 tentang "Blue Print Peningkatan Nilai Tambah dan Daya saing Produk Pertanian dengan Pemberian Intensif Bagi Tumbuhnya Industri Pedesaan", telah ditetapkan singkong sebagai komoditas prioritas yang tidak hanya berperan sebagai diversifikasi pangan pokok, melainkan juga sebagai substitusi impor (substitusi impor gandum) (Hariyono, dkk, 2014). Surya dkk (2016) menyatakan bahwa tanaman ketela pohon atau singkong termasuk tanaman umbiumbian yang mengandung karbohidrat, serat dan zat gizi lainnya yang tinggi. Akan tetapi, realitas 
dilapangan menunjukkan bahwa pemanfaatan ketela pohon sebagai bahan makanan masih belum maksimal dimana sebagian besar hanya diolah menjadi keripik atau tepung gaplek. Selain itu, terdapat banyak kendala dalam mengembangkan komoditas tersebut seperti produksi dan luas areal yang menurun, harga yang rendah, pemasaran yang sulit, dan teknologi pengolahan yang belum memadai.

Berdasarkan data Badan Pusat Statistik Provinsi Jawa Timur (2017) dan penelitian Hariyono, dkk (2014) menyatakan bahwa Kabupaten Bondowoso merupakan salah satu sentra produksi olahan ketela pohon di Jawa Timur. Produk khas olahan ketela pohon di Bondowoso yaitu tape dan keripik ketela, namun produk tersebut memiliki nilai ekonomis yang rendah dan tidak tahan lama. Wilayah Kabupaten Bondowoso juga termasuk dalam klaster pengembangan agroindustri intermediate ketela pohon yang masih relevan selain daerah Situbondo, Nganjuk, Bojonegoro, Tuban, Bangkalan, Sampang dan Pamekasan. Beberapa tahun terakhir ini telah ditemukan beberapa produk olahan baru dari ketela pohon yaitu tepung mocaf dan tepung cassava yang memiliki nilai ekonomis yang tinggi dan belum banyak diproduksi oleh masyarakat.

Menurut Djuwardi (2005), tepung cassava merupakan salah satu produk turunan yang diperoleh dari pengolahan ubi kayu atau ketela pohon. Produk ini juga disebut sebagai cassava flour yang berbeda dengan tepung tapioka, tepung gaplek dan mocaf. Tepung cassava atau tepung ubi kayu diperoleh dari ubi kayu atau ketela pohon yang diolah melalui proses pengupasan, pencucian, pemotongan atau sawut, perendaman, pengeringan dan penggilingan sehingga menghasilkan tepung. Sunarsi dkk (2011) menyatakan bahwa tepung cassava diperoleh dengan memanfaatkan seluruh bagian dari ubi kayu segar. Kandungan gizi yang baik dibandingkan jenis tepung yang lain, tepung cassava setiap 100 gr terdapat karbohidrat sebesar 88.20 gr.

Salah satu produsen tepung cassava di Kabupaten Bondowoso yaitu UD. Nula Abadi. UD. Nula Abadi merupakan produsen penghasil olahan berbagai jenis tepung yang berada di Kabupaten Bondowoso. Agroindustri ini bergerak dalam bidang olahan tanaman pangan menjadi produk yang memiliki daya saing tinggi dan belum banyak tersedia di pasaran. Salah satu olahan unggulan dan merupakan produk baru dari agroindustri tersebut yaitu tepung cassava. Saat ini, tepung cassava di Kabupaten Bondowoso belum banyak pesaingnya, dikarenakan minimnya pengetahuan dan teknologi untuk menghasilkan olahan tepung yang berkualitas.

Produksi tepung cassava setiap tahunnya berkisar antara $\pm 250 \mathrm{~kg}$, produksi tersebut masih tergolong sangat rendah jika dibandingkan dengan produktivitas ketela pohon. Produksi yang masih kecil akan mempengaruhi pendapatan dan keuntungan dari agroindustri. Tepung cassava saat ini dijual dengan harga Rp. $25.000 / \mathrm{kg}$. Harga tersebut relatif lebih mahal dibandingkan dengan produk tepung ketela pohon seperti taipoka dan mocaf. Harga produk yang relatif mahal akan mempengaruhi daya beli konsumen dan penjualan produk tersebut. Pemasaran tepung cassava saat ini hanya mengandalkan konsumen tetap dan konsumen baru dari luar kota yang jumlahnya masih sangat sedikit. Pemasaran dibantu oleh pedagang besar dan pedagang besar dengan sistem pemesanan melalui media sosial, dengan margin yang terbentuk sebesar Rp. 10.000 s/d rp. 15.000/ $\mathrm{kg}$. Margin tersebut sangat tinggi mengingat saluran pemasaran yang sedikit atau tidak terlalu panjang. Ketersediaan produk yang sedikit serta produk masih belum banyak dikenal oleh masyarakat menjadi hambatan dalam pemasaran dan pengembangan tepung cassava. Oleh karena itu, perlunya untuk meneliti mengenai pemasaran dan efisiensi saluran pemasaran cassava di UD. Nula Abadi.

Selain permasalahan pemasaran, UD. Nula Abadi sebagai industri baru dalam pengolahan tepung cassava membutuhkan investasi yang tinggi, dengan tingkat kapasitas produksi yang rendah tentunya akan berpengaruh terhadap keuntungan dan pendapatan. Sehingga menjadi penting untuk diteliti mengenai efisiensi biaya dan pendapatan dari pengolahan tepung cassava.

Menurut Misgiyarta dkk (2013), daya saing produk tepung gaplek atau tepung ubi kayu sangat rendah dibandingkan dengan tepung sejenis seperti tepung terigu, tepung beras, tepung sagu. Rendahnya daya saing tepung gaplek atau tepung ubi kayu karena karakteristik tepung ubi kayu atau tepung gaplek diantaranya adalah warna kurang putih, flavor tepung kurang menarik/apeg, tekstur kurang halus, viskositas rendah, dan tidak mengembang pada saat dibuat adonan. Karakteristik tepung ubi kayu inilah 
yang dipandang sebagai sifat inferior dari tepung ubi kayu atau tepung gaplek. Hal ini senada dengan produk tepung cassava yang dihasilkan oleh UD. Nula Abadi yang sedikit peminatnya dan pemasarannya masih terbatas. Oleh karena itu, perlu dilakukan penelitian mengenai strategi pengembangan tepung cassava pada Agroindustri UD. Nula Abadi.

Penelitian terkait pemasaran produk olahan tepung ketela pohon baik berupa tepung tapioca maupun tepung gaplek telah banyak dilakukan oleh beberapa peneliti baik nasional maupun internasional, diantaranya Yulifianti dkk (2012); Darwis dkk (2010); Prihartono (2018); Riyad (2017); Ugwumba dan Onwuemeodo (2014); Rahman and Awerije (2014); dan Oladejo (2017). Hasil penelitian menunjukkan bahwa pemasaran produk olahan tepung ketela pohon relatif efisien. Sehingga ada kecenderungan keuantungan yang diperoleh oleh pelaku atau lembaga pemasaran relatif merata. Selanjutnya keterbaruan penelitian ini adalah bagaimana kaitan pemasaran dengan keuntungan yang diperoleh dan efisiensi biaya dari pengolahan tepung olahan ketela pohon khususnya tepung cassava yang masih sedikit diteliti.

Berdasarkan uraian diatas, penelitian ini bertujuan untuk: (1) mengetahui saluran pemasaran dan efisiensi pemasaran tepung cassava, (2) menganalisis efisiensi biaya dan pendapatan tepung cassava serta (3) mengetahui strategi pengembangan tepung cassava yang optimal pada agroindustri UD. Nula Abadi di Kabupaten Bondowoso. Hipotesis penelitian ini yaitu (1) pemasaran tepung cassava efisien, (2) pendapatan sudah menguntungkan dengan penggunaan biaya produksi yang efisien, dan (3) agroindustri terletak pada daerah white area.

\section{METODE PENELITIAN}

Penelitian ini dilakukan pada agroindustri UD. Nula Abadi di Desa Petung Kabupaten Bondowoso tahun 2018. Lokasi penelitian tersebut dipilih secara sengaja atau purposive method (Subandi, 2011). Pemilihan lokasi ini didasarkan atas beberapa pertimbangan. Pertama, Kabupaten Bondowoso merupakan salah satu daerah dengan produksi serta luas areal tanam ketela pohon yang cukup besar di Jawa Timur.
Kedua, UD. Nula Abadi yang terletak di Desa Petung merupakan agroindustri pengolahan tepung yang salah satu produk unggulannya yaitu tepung cassava. Ketiga, produk tepung cassava UD. Nula Abadi memiliki banyak sekali keunggulan baik gizi dan nilai ekonomisnya sehingga perlu dikembangkan.

Penentuan sampel dalam penelitian ini menggunakan metode purposive sampling dan snowball sampling (Nazir, 2003). Purposive method digunakan untuk menentukan sampel produsen. Produsen digunakan untuk mengetahui proses produksi dan biaya produksi serta menentukan strategi pengembangannya. Sedangkan, sampel untuk saluran, efisiensi, dan margin pemasaran pada lembaga pemasaran menggunakan metode snowball sampling. Metode pengumpulan data menggunakan wawancara, observasi dan dokumentasi.

Analisis mengenai saluran pemasaran, efisiensi dan margin pada pemasaran tepung cassava UD. Nula Abadi di Kabupaten Bondowoso menggunakan analisis deskriptif. Adapun perhitungan margin dan efisiensi pemasaran digunakan rumus sebagai berikut:

- Margin pemasaran

Margin pemasaran menurut Sudiyono (2002), merupakan selisih harga ditingkat konsumen dengan harga ditingkat produsen yang dirumuskan dengan:

$$
\mathrm{Mp}=\mathrm{Pr}-\mathrm{Pf} .
$$

Keterangan:

$\mathrm{Mp}=$ Margin pemasaran

$\mathrm{Pr} \quad=$ Harga di tingkat konsumen $(\mathrm{Rp} / \mathrm{kg})$

$\mathrm{Pf}=$ Harga di tingkat produsen $(\mathrm{Rp} / \mathrm{kg})$

Kriteria pengambilan keputusan yaitu semakin kecil nilai margin pemasaran maka semakin efisien suatu pemasaran, dan begitupula sebaliknya. Pemasaran juga dapat dikatakan efisien apabila nilai harga yang diterima petani kakao lebih besar dari nilai margin pemasaran keseluruhan.

Share biaya:

$$
\begin{array}{ll}
\text { SBij } & =(\text { cij }:(\mathrm{Pr}-\mathrm{Pf})) \times 100 \% \\
\mathrm{Cij} & =\mathrm{Hjj}-\mathrm{Hbj}-\mathrm{Iij}
\end{array}
$$

Share Keuntungan:

$$
\begin{array}{ll}
\text { Skj } & =(\pi \mathrm{ij}:(\mathrm{Pr}-\mathrm{Pf})) \times 100 \% \\
\pi \mathrm{ij} & =\mathrm{Hjj}-\mathrm{Hbj}-\mathrm{cij}
\end{array}
$$


Keterangan:

Sbij = Bagian biaya untuk melaksanakan fungsi pemasaran ke-i oleh lembaga pemasaan ke-j.

$\mathrm{Cij}=$ Biaya untuk melaksanakan fungsi pemasaran ke-i oleh lembaga pemasaran ke-j.

$\operatorname{Pr}=$ Harga di tingkat konsumen

Pf = Harga di tingkat petani

$\mathrm{Hjj}=$ Harga jual lembaga pemasaran ke-j.

$\mathrm{Hbj}=$ Harga beli lembaga pemasaran ke-j.

$\pi \mathrm{ij}=$ Keuntungan lembaga pemasaran ke-j.

Skj = Bagian keuntungan lembaga pemasaran ke-j.

Kriteria pengambilan keputusan:

- Apabila Skj > Sbi maka saluran pemasaran tersebut menguntungkan.

- Apabila Skj < Sbi maka saluran pemasaran tersebut tidak menguntungkan.

- Efisiensi pemasaran

Menurut Soekartawi (2002), efisiensi pemasaran digunakan untuk mengetahui efisiensi yang dilakukan dengan cara menghitung total biaya pemasaran dibagi dengan nilai produk yang dipasarkan dikalikan $100 \%$ yang dapat dirumuskan sebagai berikut:

$$
\text { Eps }=\text { TB/TNP } \times 100 \%
$$

Keterangan:

Eps = Efisiensi pemasaran (\%)

$\mathrm{TB}=$ Total biaya pemasaran $(\mathrm{Rp} / \mathrm{kg})$.

$\mathrm{TNP}=$ Total nilai produk $(\mathrm{Rp} / \mathrm{kg})$.

Kriteria pengambilan keputusan yaitu:

- Jika nilai Eps $>50 \%$ maka efisien.

- Jika nilai Eps $<50 \%$ maka tidak efisien.

Analisis permasalahan kedua terkait pendapatan dan efisiensi biaya produksi dijawab menggunakan analisis efisiesi biaya dan pendapatan sebagai berikut:

- Pendapatan

Menurut Soekartawi (1995), pendapatan usaha adalah selisih antara penerimaan (pendapatan kotor) dengan semua biaya baik biaya tetap maupun biaya variabel yang dapat dirumuskan sebagai berikut:

$$
\begin{aligned}
\pi \pi & =\mathrm{TR}-\mathrm{TC} \\
\mathrm{TR} & =\mathrm{P} \times \mathrm{Q} \\
\mathrm{TC} & =\mathrm{TFC}+\mathrm{TVC}
\end{aligned}
$$

Keterangan:

$$
\begin{aligned}
\pi & =\text { Pendapatan agroindustri } \\
\mathrm{TR}= & \text { Total penerimaan (revenue) dari } \\
& \text { hasil produksi (Rp) } \\
\mathrm{TC} \quad & \text { Total biaya }(\text { cost }) \text { dalam proses } \\
& \text { Produksi }(\mathrm{Rp}) \\
\mathrm{P} \quad= & \text { Harga produk }(\mathrm{Rp}) \\
\mathrm{Q} & =\text { Jumlah produk yang dihasilkan }(\mathrm{kg}) \\
\mathrm{TFC} \quad= & \text { Total biaya tetap agroindustri }(\mathrm{Rp}) \\
\mathrm{TVC}= & \text { Total biaya variabel agroindustri }(\mathrm{Rp})
\end{aligned}
$$

Kriteria pengambilan keputusan:

1. Jika TR > TC, maka usaha agroindustri tepung cassava memperoleh keuntungan.

2. Jika $\mathrm{TR}=\mathrm{TC}$, maka usaha agroindustri tepung cassava berada pada kondisi BEP (Break Even Point) artinya usaha tepung cassava tidak menguntungkan dan tidak merugikan.

3. Jika $\mathrm{TR}<\mathrm{TC}$, maka usaha agroindustri tepung cassava mengalami kerugian.

\section{- Efisiensi Biaya}

Menurut Soekartawi (1995), analisa yang digunakan untuk mengetahui tingkat efisiensi suatu usaha adalah analisa $\mathrm{R} / \mathrm{C}$ ratio. $\mathrm{R} / \mathrm{C}$ ratio dikenal sebagai perbandingan antara total penerimaan dan total biaya yang dikeluarkan yang dapat dirumuskan sebagai berikut:

$\mathrm{R} / \mathrm{C}$ ratio $=\mathrm{TR} / \mathrm{TC}$

Keterangan:

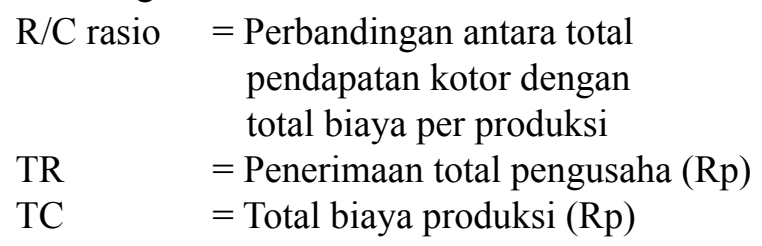

Kriteria pengambilan keputusan:

- $\mathrm{R} / \mathrm{C}$ ratio $\leq 1$, maka penggunaan biaya produksi pada agroindustri tepung cassava tidak efisien.

- $\mathrm{R} / \mathrm{C}$ ratio $>1$, maka penggunaan biaya produksi pada agroindustri tepung cassava efisien.

Analisis permasalahan ketiga terkait pengembangan tepung cassava menggunakan analisis SWOT (Strengths, Weaknesses, Opportunities and Threats) dengan langkahlangkah sebagai berikut:

- Analisis faktor-faktor strategi internal dan eksternal. 
- Menggambarkan posisi kompetitif relative.

- Menggambarkan diagram analisis SWOT.

- Membuat matrik internal dan eksternal.

- Membuat matriks SWOT

Kriteria penggambilan keputusan:

- Apabila agroindustri terletak di daerah White Area (bidang kuat-berpeluang), maka agroindustri tersebut memiliki peluang pasar yang prospektif dan memiliki kompetensi untuk mengerjakannya.

- Apabila agroindustri terletak di daerah Grey Area (bidang lemah-berpeluang), maka agroindustri tersebut memiliki peluang pasar yang prospektif, tetapi tidak memiliki kompetensi untuk mengerjakannya.

- Apabila agroindustri terletak di daerah Grey Area (bidang kuat-terancam), maka agroindustri tersebut cukup kuat dan memiliki kompetensi untuk mengerjakannya, tetapi peluang pasar sangat mengancam.

- Apabila agroindustri terletak di daerah Black Area (bidang lemah-terancam), maka agroindustri tersebut tidak memiliki peluang pasar dan tidak memiliki kompetensi untuk mengerjakannya.

\section{HASIL DAN PEMBAHASAN}

Saluran dan efisiensi pemasaran tepung cassava pada agroindustri Nula Abadi di Kabupaten Bondowoso

Sistem saluran pemasaran tepung cassava di agroindustri UD. Nula Abadi terdapat 3 jenis saluran pemasaran. Saluran pemasaran dan share produk yang terbentuk seperti Gambar 1. dengan melibatkan lembaga pemesaran yaitu pedagang besar dan pengecer. Masing-masing saluran pemasaran akan dijelaskan sebagai berikut:
Keterangan:

Produsen - Pedagang Pedagang besar Pengecer - Agroindustri/Konsumen rumah tangga

$$
\text { : Saluran Pemasaran II Yaitu }
$$

Produsen - Pedagang Pedagang besar -

Konsumen rumah tangga

: Saluran Pemasaran III Yaitu

Produsen - Pengecer - Konsumen rumah tangga

\section{Saluran Pemasaran Tepung Cassava pada Agroindustri UD. Nula Abadi \\ - Saluran I}

Saluran pemasaran I terdiri atas produsen, pedagang besar, pengecer dan konsumen rumah tangga. Produsen akan menjual ke pedagang besar yang sebelumnya telah melakukan pemesanan. Umumnya pedagang besar membeli produk $30-35 \mathrm{Kg}$ setiap bulannya untuk disalurkan ke pengecer. Pedagang pedagang besar mendapatkan share produk $76,2 \%$ dari produsen. Selanjutnya, pedagang besar menjual kepada pengecer yang pada umumnya merupakan teman akrab maupun teman kerja yang sebelumnya sudah melakukan pemesanan produk. Pemasaran yang dilakukan oleh pedagang besar dilakukan melalui media online dan secara langsung. Pemasaran secara online umumnya dilakukan oleh teman atau rekan kerja yang ada di luar Kota Bondowoso, sedangkan pemasaran langsung dilakukan di Kota Bondowoso. Pengecer disini berfungsi sebagai penyalur produk sampai ketangan konsumen dengan share produk sebesar 16,7\%. Aliran produk pada saluran pertama umumnya merupakan konsumen dan lembaga yang saling dekat dan sudah kenal satu sama lainnya.

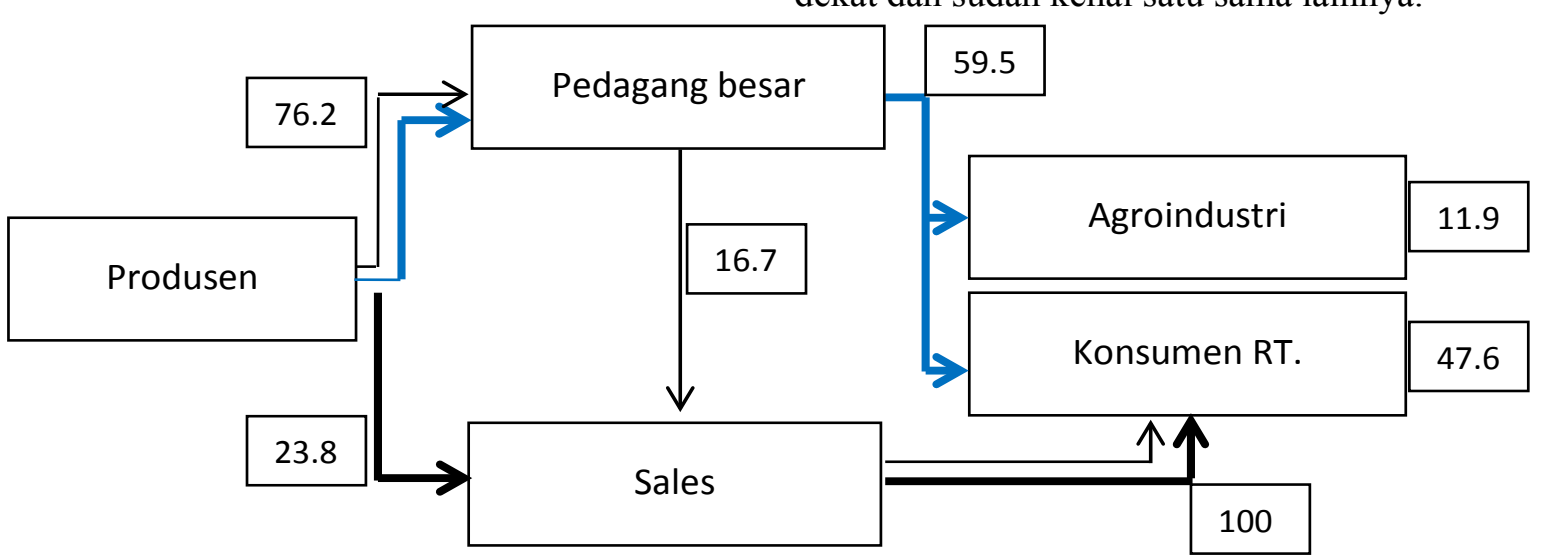

Gambar 1. Saluran pemasaran dan share produk tepung cassava pada agroindustri UD. Nula Abadi tahun 2018. 


\section{- Saluran II}

Saluran pemasaran II terdiri atas produsen, pedagang besar dan konsumen rumah tangga maupun konsumen potensial (agroindustri). Produsen menjual tepung cassava dengan ukuran 500/1000 gr ke pedagang besar yang umumnya akan memesan terlebih dahulu 2-3 hari sebelumnya. Tepung yang sudah bisa diambil akan diinformasikan kepada pedagang besar melalui media sosial (whatapps) dan selanjutnya di ambil oleh pedagang besar. Harga jual setiap eceran $1 \mathrm{Kg}$ yaitu Rp25.000 dan Rp. 24.000/Kg untuk setuap pembelian diatas $15 \mathrm{Kg}$. Pedagang besar selanjutnya akan mendistribusikan produk ke konsumen yang sebelumnya juga memesan terlebih dahulu dan juga melalui media sosial (online) untuk luar kota. Share produk untuk pedagang besar sebesar $59,5 \%$ dari produsen yang akan disalurkan ke konsumen. Umumnya konsumen yang membeli merupakan langganan atau konsumen tetap. Harga jual untuk setiap $1 \mathrm{~kg}$ tepung ke konsumen yaitu Rp. 30.000- 35.000/kg. Umumnya konsumen membeli tepung cassava untuk membuat kue kering, adonan, makanan kesehatan dan makanan diet karena kandungan gizi yang tinggi serta kaya serat dengan share produk sebesar $47,6 \%$. Sedangkan agroindustri diolah menjadi makanan kesehatan untuk diet, balita dan manula dalam bentuk kue, bubur, mie dan lainnya dengan share produk sebesar 11,9\%.

- Saluran III

Saluran pemasaran III yang terbentuk terdiri atas produsen, pengecer dan konsumen rumah tangga. Produsen menjual produk langsung ke pengecer dimana pengecer langsung mengambil ke produsen dengan melakukan pemesanan sebelumnya dengan share produk sebesar 23,8\%. Produsen juga akan mengantar produk ketika kosumennya merupakan instansi pemerintahan yang akan digunakan sebagai bahan pameran atau pelatihan. Pengecer pada umumnya merupakan orang-orang yang bekerja di instansi pemerintahan yang juga terlibat dalam pengembangan agroindustri ini. Pengecer tersebut diantaranya dinas koperasi, dinas pertanian, penyuluh dan dinas ketahanan pangan maupun lembaga penelitian. Harga jual yang diterima konsumen berkisar antara Rp. 35.000Rp. $37.000 / \mathrm{kg}$
Efisiensi Pemasaran Pemasaran Tepung Cassava Pada Agroindustri UD. Nula Abadi

Efisiensi pemasaran tepung cassava pada agroindustri UD. Nula Abadi didasarkan pada margin pemasaran, share dan efisiensi pemasaran itu sendiri.

\section{- Margin Pemasaran}

Margin pemasaran merupakan selisis harga yang harus dibayar konsumen dengan harga yang diterima produsen. Berikut Tabel 1. yang menyajikan margin pemasaran pada masing-masing saluran pemasaran tepung cassava pada UD. Nula Abadi:

Tabel 1. Margin Pemasaran Tepung Cassava pada UD. Nula Abadi.

\begin{tabular}{cccc}
\hline $\begin{array}{c}\text { Saluran } \\
\text { Pemasaran } \\
(\mathrm{Rp} / \mathrm{kg})\end{array}$ & $\begin{array}{c}\text { Harga } \\
\text { Produsen } \\
(\mathrm{Rp} / \mathrm{kg})\end{array}$ & $\begin{array}{c}\text { Harga } \\
\text { Konsumen } \\
(\mathrm{Rp} / \mathrm{kg})\end{array}$ & $\begin{array}{c}\mathrm{MP} \\
(\mathrm{Rp} / \\
\mathrm{kg})\end{array}$ \\
\hline Saluran I & 25.000 & 38.500 & \\
Saluran II & 25.000 & 34.000 & 9.000 \\
Saluran III & 25.000 & 36.520 & \\
\hline
\end{tabular}

Sumber: Data primer diolah tahun (2018).

Berdasarakan Tabel 1. dapat diketahui bahwa saluran I mempunyai margin pemasaran Rp. 13.500/kg. Saluran II sebesar Rp. 9.000/ $\mathrm{kg}$ dan saluran III sebesar Rp. 11.520/kg. Berdasarkan data tersebut dapat disimpulkan bahwa saluran pemasaran II merupakan saluran yang paling efisien karena mempunyai nilai margin pemasaran yang paling kecil dari saluran pemasaran lainnya. Semakin kecil nilai margin pemasaran maka saluran pemasaran semakin efisien. Selain itu, saluran II merupakan saluran yang relatif pendek dibandingkan dengan saluran lainnya. Hal ini sesuai dengan penelitian Prihartono (2018); Riyad (2017); Ugwumba dan Onwuemeodo (2014); Rahman and Awerije (2014); dan Oladejo (2017) yang menyatakan bahwa saluran pemasaran yang paling efisien adalah saluran yang paling pendek. Namun hal ini berkebalikan dengan penelitian Asmarantaka (2012) yang menyatakan bahwa saluran pemasaran yang panjang juga akan efisien jika masingmasing lembaga pemasaran merasa puas dengan saluran tersebut.

- Share biaya dan keuntungan

Share biaya merupakan bagian biaya untuk melaksanakan fungsi pemasaran oleh lembaga pemasaran selanjutnya, sedangkan 
share keuntungan yaitu bagian keuntungan lembaga pemasaran. Berikut Tabel 2. yang menyajikan nilai keseluruhan share biaya dan keuntungan pada masing-masing saluran pemasaran tepung cassava pada UD. Nula Abadi di Kabupaten Bondowoso:

Tabel 2. Nilai share Keuntungan dan Biaya pemasaran Tepung Cassava pada UD. Nula Abadi.

\begin{tabular}{lrr}
\hline $\begin{array}{c}\text { Saluran } \\
\text { Pemasaran }\end{array}$ & $\begin{array}{c}\text { Share } \\
\text { Keuntungan (\%) }\end{array}$ & $\begin{array}{c}\text { Share } \\
\text { Biaya (\%) }\end{array}$ \\
\hline Saluran I & 81,6 & 18,4 \\
Saluran II & 83,6 & 16,4 \\
Saluran III & 73,9 & 26,1 \\
\hline \multicolumn{2}{c}{ Sumber: Data primer diolah tahun (2018). }
\end{tabular}

Berdasarkan Tabel 2. diketahui bahwa total bagian keuntungan pada saluran I sebesar $81,6>18,4$ dari share biaya. Saluran II memiliki share keuntungan sebesar 83,6>16,4 dari share biaya dan saluran III sebesar 73,9 > 26,1 dari share biaya. Berdasarkan data tersebut dapat disimpulkan bahwa semua saluran menguntungkan.

- $\quad$ Efisiensi Pemasaran (Eps)

Efisiensi pemasaran merupakan total biaya pemasaran yang dikeluarkan oleh lembaga pemasaran selama kegiatan pemasaran dibagi dengan total nilai produk. Berikut Tabel 3 . yang menyajikan hasil efisiensi pemasaran pada masing-masing saluran pemasaran tepung cassava pada UD. Nula Abadi:

Tabel 3. Efisiensi Pemasaran Tepung Cassava pada UD. Nula Abadi.

\begin{tabular}{lrcc}
\hline $\begin{array}{c}\text { Saluran } \\
\text { Pemasaran }\end{array}$ & $\begin{array}{c}\text { Biaya } \\
(\mathrm{Rp} / \mathrm{kg})\end{array}$ & $\begin{array}{c}\text { Harga } \\
\text { Konsumen } \\
(\mathrm{Rp} / \mathrm{kg})\end{array}$ & $\begin{array}{c}\text { Efisiensi } \\
\text { Pemasaran } \\
(\%)\end{array}$ \\
\hline Saluran 1 & 6.801 & 38.500 & 17,66 \\
Saluran II & 5.301 & 34.000 & 15,59 \\
Saluran III & 9.520 & 36.520 & 26,07 \\
\hline Sumber: Data primer diolah tahun (2018).
\end{tabular}

Berdasarkan Tabel 3. diketahui bahwa nilai efisiensi pemasaran pada saluran pemasaran I sebesar $17,66 \%$, saluran pemasaran II $15.59 \%$ dan saluran pemasaran III sebesar 26,07\%. Berdasarkan data tersebut dapat disimpulkan bahwa semua saluran pemasaran adalah efisien.

Saluran pemasaran II merupakan saluran pemasaran yang paling efisien dari saluran lainnya. Hal ini dikarenakan saluran pemasaran II memiliki nilai yang paling kecil diantara saluran pemasaran yang lainnya. Saluran pemasaran II menjadi saluran yang paling efisien karena memiliki biaya pemasaran yang paling rendah dan harga di tingkat konsumen juga paling rendah diantara saluran pemasaran lainnya. Hal ini sesuai dengan penelitian Rahman and Awerije (2014); dan Oladejo (2017) yang menunjukkan bahwa saluran pemasaran yang efisien bisa ditunjukkan dari tingkat harga yang relatif rendah dengan biaya yang rendah pula.

\section{Analisis Pendapatan dan Efisiensi Biaya Tepung Cassava Pada Agroindustri UD. Nula Abadi di Kabupaten Bondowoso.}

Pendapatan tepung cassava pada agroindustri UD. Nula Abadi menguntungkan dan efisiensi apabila bernilai positif dan nilai $\mathrm{R} / \mathrm{C}$ ratio lebih besar dari 1 . Berikut ditampilkan jumlah pendapatan dan efisiensi biaya produksi tepung cassava pada agroindustri UD. Nula Abadi:

\section{- Pendapatan tepung cassava}

Pendapatan tepung cassava pada agroindustri UD. Nula Abadi di Kabupaten Bondowoso dapat dilihat pada Tabel 4.

Tabel 4. Total biaya produksi tepung cassava pada agroindustri UD. Nula Abadi tahun 2018.

\begin{tabular}{|c|c|c|}
\hline No. & Uraian & $\begin{array}{l}\text { Nilai (Rp/ } \\
\text { Produksi)) }\end{array}$ \\
\hline 1. & Total Biaya Tetap & $1.749 .500,00$ \\
\hline \multirow[t]{10}{*}{2.} & Total Biaya Variabel & $1.775 .958,33$ \\
\hline & a. Ketela Pohon & $700.000,00$ \\
\hline & $\begin{array}{l}\text { b. Kemasan } \\
\text { (Plastik, Stiker) }\end{array}$ & $311.250,00$ \\
\hline & c. Garam & $250.000,00$ \\
\hline & $\begin{array}{l}\text { d. Natrium } \\
\text { Metabisulfit }\end{array}$ & $15.000,00$ \\
\hline & e. Solar & $25.750,00$ \\
\hline & f. Listrik & $20.000,00$ \\
\hline & g. Tenaga Kerja & $420.000,00$ \\
\hline & h. Bensin & $7.500,00$ \\
\hline & $\begin{array}{l}\text { Total Biaya }(\mathrm{Rp} / \text { Proses } \\
\text { Produksi) }\end{array}$ & $3.525 .458,33$ \\
\hline
\end{tabular}

Berdasarkan Tabel 4. diketahui bahwa total biaya produksi tepung cassava setiap kali 
berproduksi sebesar Rp. 3.525.458,33 dimana setiap berproduksi sebanyak $250 \mathrm{~kg}$. Total biaya tersebut didapatkan dari total biaya tetap dengan biaya variabel sebesar Rp. 1.749.500,00 dan Rp. $1.775 .958,33$. Hasil perhitungan biaya variabel dan biaya tetap tersebut selanjutnya digunakan untuk menghitung jumlah pendapatan tepung cassava pada agroindustri UD. Nula Abadi yang ditampilkan pada Tabel 5. sebagai berikut:

Tabel 5. Total Pendapatan per proses produksi tepung cassava pada agroindustri UD. Nula Abadi tahun 2018

\begin{tabular}{|c|c|c|}
\hline No. & Uraian & Nilai (Rp/Produksi) \\
\hline \multirow[t]{3}{*}{1.} & Total Penerimaan (TR) & $6.250 .000,00$ \\
\hline & a. Kuantitas $(\mathrm{Kg})$ & 250,00 \\
\hline & b. Harga produk & $25.000,00$ \\
\hline \multirow[t]{2}{*}{2.} & Total Biaya (TC) & $3.525 .458,33$ \\
\hline & TotalPendapatan & $2.724 .541,67$ \\
\hline
\end{tabular}

Berdasarkan Tabel 5. Diketahui bahwa total pendapatan yang diterima oleh agroindustri UD. Nula Abadi sebesar Rp. 2.724.541,67 per proses produksinya. Nilai tersebut didapatkan dari pengurangan total penerimaan sebesar Rp. 6.250.000,00 dengan total biaya sebesar Rp. 3.525.458,33. Pendapatan bernilai positif dengan total penerimaan lebih besar dibandingkan total biaya. Sehingga, dapat disimpulkan bahwa pendapatan tepung cassava pada agroindustri UD. Nula Abadi tergolong menguntungkan.

- Efisiensi biaya produksi

Efisiensi biaya menggambarkan rasio penggunaan biaya dalam memproduksi tepung cassava untuk menghasilkan keuntungan bagi produsennya. Berikut ditampilkan hasil analisis efisiensi biaya menggunakan $\mathrm{R} / \mathrm{C}$ ratio:

Tabel 6. Analisis efisiensi biaya produksi tepung cassava pada agroindustri UD. Nula Abadi pada tahun 2018.

\begin{tabular}{llc}
\hline No. & \multicolumn{1}{c}{ Uraian } & Nilai (Rp/Produksi) \\
\hline 1. & Total Penerimaan (TR) & $6.250 .000,00$ \\
2. & Total Biaya (TC) & 3.525 .458 .33 \\
3. & Total Pendapatan & $2.724 .541,67$ \\
\hline \multicolumn{3}{l}{ R/C ratio } \\
Sumber: Data primer diolah tahun (2018).
\end{tabular}

Berdasarkan Tabel 6. diketahui bahwa nilai $\mathrm{R} / \mathrm{C}$ ratio sebesar 1,77 . $\mathrm{R} / \mathrm{C}$ ratio sebesar 1,77 artinya bahwa setiap penggunaan Rp. 1 biaya untuk membuat tepung cassava, akan mendapatkan penerimaan sebesar Rp. 0.77 atau keuntungan yang didapatkan oleh agroindustri sebesar Rp. 0.77. Berdasarkan hasil analisis tersebut juga dapat disimpulkan bahwa biaya produksi tepung cassava pada agroindustri UD. Nula Abadi efisien. Hal ini sejalan dengan penelitian Yulifianti dkk (2012); Darwis dkk (2010) yang menyatakan bahwa usaha pengolahan saingkong menjadi tepung merupakan usaha yang menguntungkan karena harga singkong yang relatif murah sehingga jika dilakukan pengolahan akan meningkatkan nilai tambah.

\section{Analisis SWOT}

Alat analisis digunakan untuk meramalkan posisi agroindustri dan merumuskan strategi yang terbaik dengan cara mengidentifikasi faktor internal serta faktor eksternal. Hasil analisis faktor internal dapat dilihat pada Tabel 7.

Tabel 7. Analisis Faktor Internal Pada Agroindustri Tepung Cassava di UD. Nula Abadi.

\begin{tabular}{|c|c|c|c|c|}
\hline No. & Faktor Kekuatan & Bobot & Rating & Nilai \\
\hline 1 & $\begin{array}{l}\text { Bahan baku } \\
\text { tercukupi }\end{array}$ & 0,09 & 3 & 0,27 \\
\hline 2 & $\begin{array}{l}\text { Penggunaan } \\
\text { teknologi tepat } \\
\text { guna }\end{array}$ & 0,12 & 4 & 0,47 \\
\hline 3 & $\begin{array}{l}\text { Agroindustri } \\
\text { memiliki ijin } \\
\text { PIRT }\end{array}$ & 0,12 & 4 & 0,47 \\
\hline 4 & $\begin{array}{l}\text { Produk tepung } \\
\text { cassava } \\
\text { memiliki banyak } \\
\text { keunggulan }\end{array}$ & 0,12 & 4 & 0,47 \\
\hline
\end{tabular}

\begin{tabular}{|c|c|c|c|c|}
\hline \multicolumn{2}{|c|}{ Total Kekuatan } & \multirow{2}{*}{$\begin{array}{c}0,44 \\
\text { Bobot }\end{array}$} & \multirow{2}{*}{$\begin{array}{c}15 \\
\text { Rating }\end{array}$} & \multirow{2}{*}{$\begin{array}{l}1,69 \\
\text { Nilai }\end{array}$} \\
\hline No. & $\begin{array}{c}\text { Faktor } \\
\text { Kelemahan }\end{array}$ & & & \\
\hline 1 & $\begin{array}{l}\text { Kapasitas } \\
\text { Produksi terbatas }\end{array}$ & 0,17 & 3 & 0,50 \\
\hline 2 & $\begin{array}{l}\text { Rendahnya } \\
\text { modal usaha }\end{array}$ & 0,06 & 1 & 0,06 \\
\hline 3 & $\begin{array}{l}\text { Harga tepung } \\
\text { cassava cukup } \\
\text { mahal }\end{array}$ & 0,11 & 2 & 0,22 \\
\hline 4 & $\begin{array}{l}\text { Desain produk } \\
\text { kurang menarik, }\end{array}$ & 0,11 & 2 & 0,22 \\
\hline 5 & $\begin{array}{l}\text { Pemasaran } \\
\text { terbatas }\end{array}$ & 0,11 & 2 & 0,22 \\
\hline \multicolumn{2}{|c|}{ Total Kelemahan } & 0,56 & 10 & 1,22 \\
\hline \multicolumn{2}{|c|}{ Total Faktor Internal } & 1,00 & 25 & 2,91 \\
\hline
\end{tabular}


Berdasarkan Tabel 7. dapat diketahui terdapat beberapa faktor internal yaitu faktor kekuatan dan faktor kelemahan yang terdapat pada agroindustri UD. Nula Abadi. Faktor-faktor internal pada agroindustri tersebut diantaranya yaitu:

- Bahan baku melimpah $\left(\mathrm{S}_{1}\right)$

Bahan baku yang dibutuhkan untuk pembuatan tepung cassava yaitu ketela pohon. Ketela bohon di Kabupaten Bondowoso sangat mudah diperoleh karena merupakan salah satu komoditas yang banyak dibudidayakan.

- Penggunaan teknologi tepat guna $\left(\mathrm{S}_{2}\right)$

UD. Nula Abadi dalam proses produksi sudah menggunakan teknologi mesin yaitu alat penggiling, pengemasan serta timbangan listrik. Pemasaran juga sudah menggunakan media sosial yang dapat memudahkan dan membantu promosi serta penjualan produk sampai ketangan konsumen. Adanya teknologi komunikasi dirasa sangat membantu dalam komunikasi serta mobilisasi dengan lembaga pemasaran maupun konsumen.

- $\quad$ Agroindustri memiliki ijin PIRT $\left(\mathrm{S}_{3}\right)$

Agroindustri UD. Nula Abadi di Kabupaten Bondowoso sudah memiliki ijin PIRT atau usaha pembuatan makanan dari dinas terkait. Olahan tepung cassava dan lainnya sudah didaftarkan dengan nomor ijin PIRT No: 2063511010249-18 pada tahun 2013.

- Produk tepung cassava memiliki banyak keunggulan $\left(\mathrm{S}_{4}\right)$

Tepung cassava dibuat tanpa menggunakan bahan pengawet, perasa, pewarna sehingga memiliki cita rasa yang gurih dan beraroma khas ketela pohon. Memiliki kandungan gizi yang baik dibandingkan jenis tepung yang lain, tepung cassava setiap 100 gr terdapat karbohidrat sebesar 88,20 gr.

- Kapasitas produksi terbatas $\left(\mathrm{W}_{1}\right)$

UD. Nula Abadi hanya memproduksi tepung cassava sebanyak 2 kali dalam setahun. Skala usaha yang masih kecil serta permintaan konsumen yang belum terlalu besar membuat produsen memproduksi tepung masih dalam skala produksi kecil. Setiap produksi membutuhkan bahan baku sebesar 1 ton untuk diolah menjadi $250 \mathrm{~kg}$ tepung cassava.

- Rendahnya modal usaha $\left(\mathrm{W}_{2}\right)$

Modal menjadi salah satu faktor penting dalam menjalankan atau membuat suatu usaha. Agroindustri UD. Nula Abadi yang baru merintis usaha mengalami kendala modal dalam mengembangkan usahanya ke tingkat yang lebih besar. Modal usaha dapat digunakan untuk menyediakan sarana prasarana serta meningkatkan teknologi baru sehingga produksi lebih besar dan efisien. Minimnya modal usaha berdampak pada produksi dan harga produk yang cukup mahal dibandingkan produk sejenis seperti tepung terigu, mocaf maupun tepung tapioka.

- Harga tepung cassava cukup mahal $\left(\mathrm{W}_{3}\right)$

Produk tepung cassava dijual dengan harga sebesar Rp. 25.000/kg. Harga tersebut masih cukup mahal dibandingkan dengan produk sejenis seperti tepung tapioca, gaplek dan mocaf. Penggunaan teknologi yang rendah serta masih mengandalkan tenaga manusia dalam proses produksi megakibatkan harga masih mahal.

- Desain produk yang kurang menarik $\left(\mathrm{W}_{4}\right)$

Desain produk meliputi label, kemasan, ukuran huruf, jenis huruf, warna dan logo yang terdapat pada kemasan suatu produk. Desain produk produk tepung cassava kurang menarik dimana belum adanya label gizi dan ukuran label yang kecil dan kemasan yang digunakan. Desain produk yang baik dan bagus harus memberikan informasi yang lengkap, menarik dan unik.

- Pemasaran terbatas $\left(\mathrm{W}_{5}\right)$

Pemasaran tepung cassava saat ini hanya tergantung pemesanan dan konsumen yang sudah menjadi pelanggan tetap. Produsen dibantu pedagang besar dan pengecer dalam menyalurkan produknya sampai ketangan konsumen. Belum banyaknya konsumen yang tahu serta harga yang cukup mahal menjadi alasan masih sulitnya pemasaran. Berikut ditampilkan hasil analisis faktor eksternal pada agroindustri Tepung cassava di UD. Nula Abadi:

Tabel 8. Analisis Faktor Eksternal Pada Agroindustri Tepung Cassava di UD. Nula Abadi.

\begin{tabular}{clccc}
\hline No. & Faktor Peluang & Bobot & Rating & Nilai \\
\hline 1 & $\begin{array}{l}\text { Rendahnya } \\
\text { pesaing dengan } \\
\text { produk yang }\end{array}$ & 0,15 & 4 & 0,61 \\
2 & $\begin{array}{l}\text { sama } \\
\text { Dukungan } \\
\text { Pemerintah } \\
\text { dalam } \\
\text { pengembangan } \\
\text { produk }\end{array}$ & 0,11 & 3 & 0,34 \\
3 & $\begin{array}{l}\text { Variasi olahan } \\
\text { banyak } \\
\text { Jangkauan pasar } \\
\text { yang luas }\end{array}$ & 0,15 & 4 & 0,61 \\
\hline & Total & 0,57 & 15 & 2,17 \\
\hline
\end{tabular}




\begin{tabular}{clccc}
\hline No. & $\begin{array}{c}\text { Faktor } \\
\text { Ancaman }\end{array}$ & Bobot & Rating & Nilai \\
\hline 1 & $\begin{array}{l}\text { Pengeringan } \\
\text { tergantung } \\
\text { cuaca }\end{array}$ & 0,25 & 3 & 0,75 \\
2 & $\begin{array}{l}\text { Pemanfaatan } \\
\text { tepung } \\
\text { cassava di } \\
\text { tingkat lokal } \\
\text { terbatas } \\
3 \text { Banyaknya } \\
\text { produk } \\
\text { sejenis } \\
\text { dengan harga } \\
\text { lebih murah, }\end{array}$ & 0,25 & 3 & 0,75 \\
& 0,11 & 2 & 0,21 \\
Total & 0,43 & 8 & 1,18 \\
\hline Total Faktor Eksternal & & 23 & 3,35
\end{tabular}

Sumber: Data primer diolah tahun (2018).

Berdasarkan Tabel 8. dapat diketahui terdapat beberapa faktor eksternal yaitu faktor peluang dan faktor ancaman yang terdapat pada agroindustri UD. Nula Abadi. Faktor-faktor eksternal pada agroindustri tersebut diantaranya yaitu:

- $\quad$ Rendahnya pesaing produk yang sama $\left(\mathrm{O}_{1}\right)$.

Produk tepung cassava di Kabupaten Bondowoso dan sekitarnya masih belum banyak dijumpai. Pesaing produk dapat dikatakan masih sedikit karena produk tersebut merupakan pengembangan dari tepung tapioka, gaplek dan mocaf.

- Adanya dukungan Pemerintah dalam pengembangan produk $\left(\mathrm{O}_{2}\right)$.

Pemerintah Kabupaten Bondowoso melalui dinas ketahanan pangan dan UMKM sangat mendukung produk-produk inovatif dan memanfaatkan sumber daya lokal. Perhatian pemerintah melalui pendampingan dan kemudahan izin dapat dijadikan peluang untuk mendapatkan dukungan lainnya baik modal, teknologi maupun pemasaran.

- Variasi olahan banyak $\left(\mathrm{O}_{3}\right)$

Produk tepung cassava merupakan bahan baku yang harus diolah kembali agar menjadi produk siap konsumsi. Banyak sekali olahan yang dapat dibuat dengan menggunakan tepung cassava diantaranya snack, kue kering, mie, bubur dan sebagai bahan complement atau campuran dari produk lainnya.

- Jangkauan pasar yang luas $\left(\mathrm{O}_{4}\right)$

Produk tepung cassava yang merupakan produk baru dan belum banyak tersedia di pasaran dapat menjadi keunggulan dalam memasarkan produknya. Belum banyaknya produk sejenes membuka peluang untuk memasarkan ke daerah-daerah yang potensial. Jangkauan pasar yang luas menjadi peluang yang bagus untuk mengembangkan produk kedepanya.

- Pengeringan tergantung cuaca $\left(\mathrm{T}_{1}\right)$.

Proses produksi tepung cassava yang masih manual sangat dipengaruhi oleh cuaca. Proses pengeringan atau penjemuran ketela pohon yang masih memanfaatkan sinar matahari akan bepengaruh ketika cuaca mendung maupun hujan.

- Pemanfaatan tepung cassava di tingkat lokal terbatas $\left(\mathrm{T}_{2}\right)$.

Masyarakat di Kabupaten Bondowoso masih belum banyak agroindustri olahan tepung menjadi produk turunannya. Ketersediaan dan pemanfaatan tepung cassava yang masih rendah akan mempengaruhi penjualan dan pengembangan produk kedepannya.

- Banyaknya produk sejenis dengan harga lebih murah $\left(\mathrm{T}_{3}\right)$.

Tepung cassava di pasaran banyak sekali pesaing produknya seperti tepung terigu, beras, tapioka, mocaf dan gaplek. Terlebih, harga produk pesaing lebih murah, sehingga perlu adanya ciri khas dari produk tersebut.

Posisi agroindustri tepung cassava di UD. Nula Abadi dapat digambarkan dalam matrik posisi kompetitif relatif pada Gambar 5.

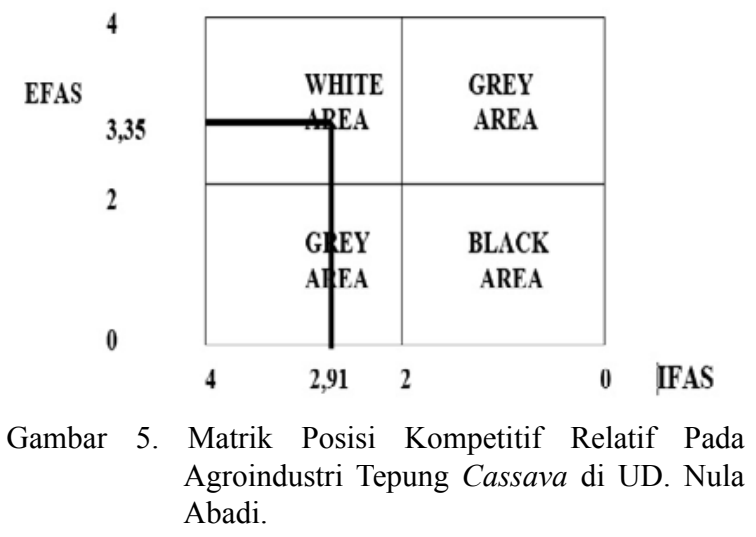

Berdasarkan Gambar 5. diketahui bahwa nilai faktor internal (IFAS) yang merupakan penjumlahan total nilai faktor kekuatan dan faktor kelemahan sebesar 2,91. Sedangkan faktor eksternal (EFAS) yang merupakan penjulahan dari total nilai faktor peluang dan ancaman sebesar 3,35. Hasil analisis yang diperoleh dengan nilai IFAS dan EFAS menempatkan agroindustri tepung cassava di UD. Nula Abadi pada posisi White Area yang artinya agroindustri tersebut memiliki peluang yang prospektif dan memiliki 
kompetensi untuk mengerjakannya. Kekuatan yang dimiliki oleh agroindustri tepung cassava diantaranya yaitu bahan baku ketela pohon yang tercukupi di Kabupaten Bondowoso, proses produksi dan pemasaran sudah menggunakan teknologi baik mesin maupun sistem informasi, agroindustri tepung cassava yang sudah memiliki ijin dengan nomor PIRT No: 2063511010249-18, memiliki banyak sekali keunggulan baik nilai gizi maupun kualitas yang ada pada tepung cassava dibandingkan dengan produk tepung dari ketela pohon.

Analisis selanjutnya yang dilakukan untuk menentukan strategi pengembangan terbaik yaitu analisis matrik IE (InternalEksternal). Matrik IE tersebut digunakan untuk mengetahui posisi agroindustri tepung cassava di UD. Nula Abadi secara lebih jelas. Perhitungan matrik IE juga dilakukan dengan mengetahui terlebih dahulu nilai faktor internal (IFAS) dan nilai faktor eksternal (EFAS) agroindustri tersebut. Hasil analisis matrik IE dapat dilihat pada Gambar 6. sebagai berikut:

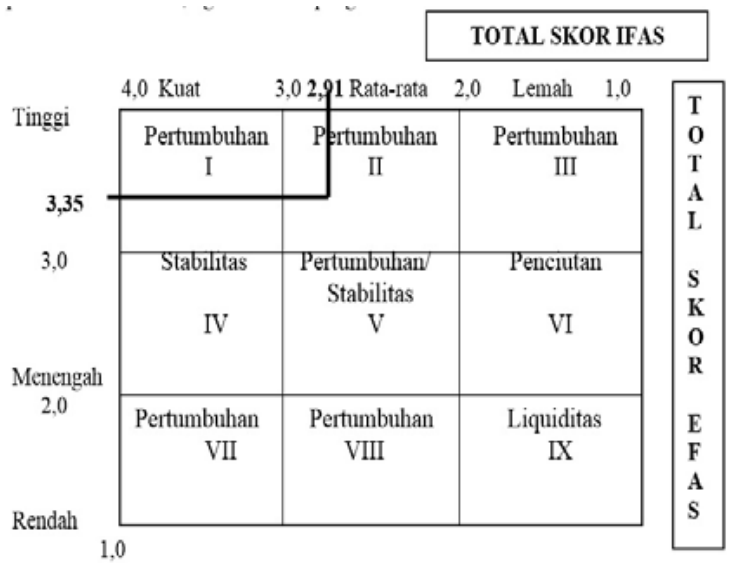

Gambar 6. Matrik Internal dan Eksternal Pada Agroindustri Tepung Cassava di UD. Nula Abadi.

Berdasarkan Gambar 6. diketahui bahwa total skor faktor internal (IFAS) sebesar 2,91 dan total skor faktor eksternal (EFAS) sebesat 3,35. Hasil dari analisis mengenai matrik IE dengan menggunakan total skor IFAS dan EFAS menunjukkan bahwa agroindustri tepung cassava di UD. Nula Abadi terletak pada bidang ke II yaitu pertumbuhan dimana kondisi agroindustri tumbuh. Pada kuadran II unit usaha ini dalam posisi tumbuh dan bina. Strategi yang dilakukan pada posisi ini adalah strategi intensif dan strategi integratif. Strategi intensif dilakukan dengan cara penetrasi pasar, pengembangan pasar dan pengembangan produk. Sedangkan strategi integratif dilakukan dengan cara integrasi kedepan (meningkatkan kendali pada distributor) dan integrasi kebelakang (kendali lebih besar pada pemasok) dan dengan konsentrasi melalui integrasi horizontal, yakni merujuk strategi yang dilakukan agroindustri pesaing.

Analisis mengenai matrik SWOT yang dilakukan pada agroindustri tepung cassava di UD. Nula Abadi digunakan untuk menggambarkan secara jelas bagaimana faktor kekuatan dan kelemahan yang dimiliki oleh agroindustri tepung cassava di UD. Nula Abadi guna untuk memanfaatkan peluang dan menghadapi ancaman dari luar. Hasil matrik SWOT agroindustri tepung cassava di UD. Nula Abadi dapat dilihat pada Tabel 9. sebagai berikut: 
Tabel 9. Hasil Analisis Matrik SWOT Eksternal Pada Agroindustri Tepung Cassava di UD. Nula Abadi.

\begin{tabular}{|c|c|c|}
\hline IFAS & $\begin{array}{l}\text { Strength (S) } \\
\text { - } \quad \text { Bahan baku tercukupi } \\
\text { - } \quad \text { Penggunaan teknologi tepat guna } \\
\text { - } \quad \text { Agroindustri memiliki ijin PIRT } \\
\text { Produk tepung cassava memiliki } \\
\quad \text { banyak keunggulan. }\end{array}$ & $\begin{array}{l}\text { Weakness }(\mathbf{W}) \\
\text { - } \quad \text { Kapasitas produksi terbatas } \\
\text { - } \quad \text { Rendahnya modal usaha } \\
\text { - } \quad \text { Harga tepung cassava } \text { cukup mahal } \\
\text { - } \quad \text { Desain produk kurang menarik } \\
\text { - } \quad \text { Pemasaran terbatas }\end{array}$ \\
\hline $\begin{array}{ll}\text { Opportunity (O) } \\
\text { - } & \text { Rendahnya pesaing } \\
& \text { dengan produk yang sama } \\
\text { - } & \text { Adanya dukungan } \\
& \text { Pemerintah dalam } \\
& \text { pengembangan produk. } \\
\text { - } & \text { Variasi olahan banyak } \\
\text { - } & \text { Jangkauan pasar yang } \\
& \text { luas. }\end{array}$ & $\begin{array}{l}\text { Strategi S-O } \\
\text { - } \text { Meningkatkan produksi dan } \\
\text { variasi olahan tepung cassava } \\
\text { dengan memanfaatkan dukungan } \\
\text { pemerintah melalui dinas terkait } \\
\text { mengingat pesaing yang masih } \\
\text { rendah, bahan baku yang masih } \\
\text { tercukupi, jangkauan pasar yang } \\
\text { masih luas dan keunggulan produk } \\
\text { sebagai pembeda dari produk lain. } \\
\text { Menambah sertifikasi ijin produk } \\
\text { seperti BPOM dengan bantuan } \\
\text { pemerintah melalui dinas terkait. } \\
\text { Penggunaan teknologi baik mesin } \\
\text { maupun sistem informasi dalam } \\
\text { memproduksi tepung cassava serta } \\
\text { mengakses pasar yang luas. }\end{array}$ & $\begin{array}{l}\text { Strategi W-O. } \\
\text { - } \quad \text { Menciptakan desain produk } \\
\text { yang menarik dan informatif } \\
\text { dengan memanfaatkan dukungan } \\
\text { pemerintah serta teknologi yang } \\
\text { ada. } \\
\text { Meningkatkan modal usaha melalui } \\
\text { bantuan dinas pemerintahan terkait } \\
\text { untuk membuat variasi olahan serta } \\
\text { menjangkau pasar yang luas. } \\
\text { Meningkatkan kapasitas produksi } \\
\text { serta variasi olahan melalui } \\
\text { bantuan pemerintah baik modal, } \\
\text { regulasi maupun teknologinya agar } \\
\text { pasar yang luas dapat dijangkau } \\
\text { mengingat masih rendahnya } \\
\text { pesaing. Sehingga, nantinya } \\
\text { dapat menurunkan harga produk } \\
\text { tersebut yang lebih kompetitif dan } \\
\text { terjangkau oleh konsumen. }\end{array}$ \\
\hline $\begin{array}{ll}\text { Threats }(\mathbf{T}) \\
\text { - } & \text { Pengeringan tergantung } \\
\text { - } & \text { cuaca. } \\
& \text { Pemanfaatan tepung } \\
& \text { cassava di tingkat lokal } \\
& \text { terbatas. } \\
\text { - } & \text { Banyaknya produk } \\
\text { sejenis dengan harga } \\
\text { lebih murah. }\end{array}$ & $\begin{array}{l}\text { Strategi S-T } \\
\text { - } \quad \text { Memproses bahan baku yang sudah } \\
\text { ada dengan melihat cuaca saat } \\
\text { produksi agar proses pengeringan } \\
\text { dilaksanakan dengan maksimal. } \\
\text { - Meningkatkan variasi produk } \\
\text { mengingat produk ini memiliki } \\
\text { keunggulan yang banyak dan } \\
\text { banyaknya produk sejenis dengan } \\
\text { harga yang murah. Adanya variasi } \\
\text { olahan dari tepung cassava dapat } \\
\text { memunculkan agroindustri baru di } \\
\text { Kabupaten Bondowoso. }\end{array}$ & $\begin{array}{l}\text { Strategi W-T } \\
\text { - } \quad \text { Meningkatkan kapasitas produksi } \\
\text { dengan memperhatikan cuaca serta } \\
\text { pemanfaatan olahan tepung cassava } \\
\text { agar dapat bersaing dengan produk } \\
\text { sejenis dengan harga yang lebih } \\
\text { murah. } \\
\text { - Menurunkan harga produk sehingga } \\
\text { pemanfaatan tepung cassava di } \\
\text { tingkat lokal semakin tinggi serta } \\
\text { berdaya saing dengan produk } \\
\text { sejenis yang memiliki harga lebih } \\
\text { murah. }\end{array}$ \\
\hline
\end{tabular}

Sumber: Data primer diolah tahun (2018).

Berdasarkan pemaparan mengenai strategi-strategi pengembangan diatas maka dapat diketahui pula strategi pengembangan yang paling baik dan sesuai dengan kondisi agroindustri tepung cassava di UD. Nula Abadi. Terletak pada bidang S-O. Strategi S-O yang didapat diterapkan oleh agroindustri tepung cassava di UD. Nula Abadi meliputi peningkatkan produksi dan variasi olahan tepung cassava dengan memanfaatkan dukungan pemerintah melalui dinas terkait mengingat pesaing yang masih rendah, bahan baku yang masih tercukupi, jangkauan pasar yang masih luas dan keunggulan produk sebagai pembeda 
dari produk lain. Penambahan sertifikasi ijin produk seperti BPOM dengan bantuan pemerintah melalui dinas terkait. Sertifikasi sangat penting untuk memberikan pandangan kepada konsumen bahwa produk sudah truji dan terdaftar oleh lembaga pembuat olahan makanan. Penggunaan teknologi baik mesin maupun sistem informasi dalam memproduksi tepung cassava serta mengakses pasar yang luas. Teknologi yang digunakan dapat menurunkan biaya, waktu dan tenaga sehingga produksi akan efisien serta memudahkan dalam kegiatan komunikasi, promosi dan lainnya dalam pemasaran. Akan tetapi strategi-strategi yang terbentuk pada analisis W-O, S-T dan W-T tidak harus diabaikan dan dapat dilakukan agar pengembangan tepung cassava dapat semaksimal mungkin.

\section{KESIMPULAN}

Saluran pemasaran tepung cassava pada UD. Nula Abadi di Kabupaten Bondowoso terdiri atas 3 saluran pemasaran. Saluran pemasaran yang pertama yaitu Produsen - Besar - Pengecer - Konsumen rumah tangga. Saluran Pemasaran kedua yaitu Produsen - Pedagang besar - Konsumen agroindustri dan akhir. Ketiga, Produsen - Pengecer - Konsumen rumah tangga. Saluran pemasaran yang paling efisien dari ketiga saluran pemasaran yaitu saluran pemasaran II (Produsen - Pedagang besar - Konsumen agroindustri dan akhir) dengan nilai Eps sebesar 16,45 \% dan bagian produk sebesar 59,5\%. Biaya produksi tepung cassava pada agroindustri UD. Nula Abadi adalah efisien dengan nilai $\mathrm{R} / \mathrm{C}$ ratio sebesar 1,77. Pedapatan tepung cassava mengguntungkan dengan total penerimaan sebesar Rp. $6.250 .000,00 /$ proses produksi dan total biaya sebesar Rp. 3.525.458,33/proses produksi. Usaha tepung cassava pada agroindustri UD. Nula Abadi di Kabupaten Bondowoso terletak pada bidang White Area atau bidang kuat berpeluang, artinya agroindustri tersebut dapat menggunakan kompetensi yang dimilikinya untuk memanfaatkan peluang yang prospektif. Strategi yang dapat diterapkan oleh agroindustri UD. Nula Abadi yang pertama yaitu peningkatkan produksi dan variasi olahan tepung cassava dengan memanfaatkan dukungan pemerintah mengingat pesaing yang masih rendah, bahan baku yang masih tercukupi, jangkauan pasar yang masih luas serta keunggulan produk sebagai pembeda dari produk lain. Kedua, menambah sertifikasi ijin produk seperti BPOM serta penggunaan teknologi baik mesin maupun sistem informasi dalam proses produksi dan pemasaran tepung cassava.

\section{DAFTAR PUSTAKA}

Asmarantaka R.W. 2012. Pemasaran Agribisnis (Agrimarketing). Bogor: IPB Press.

BPS Jawa Timur. 2017. Luasan, Produktivitas, dan Produksi Komoditi Ubi Kayu di Jawa Timur. [Serial Online] https://jatim. bps.go.id/linkTabelStatis/view/id/627. Diakses pada tanggal 2 November 2017.

Darwis V., Muslim C., dan Askin A. 2010. Usahatani dan pemasaran Ubi Kayu Serta teknologi Pengolahan Tapioka di Kabupaten Pati Provinsi Jawa Timur. Bogor (ID): Pusat Analisis Sosial Ekonomi dan Kebijakan Pertanian Republik Indonesia

Djuwardi, Anton. 2005. Cassava (Solusi Pemberagaman Kemandirian Pangan). Jakarta: Grasindo.

Hanastiti, W. R. 2013. Pengaruh Substitusi Tepung Singkong Terfermentasi dan Tepung Kacang Merah Terhadap Kadar Protein, Kadar Serat, dan Daya Terima Cake. Ilmu Kesehatan 1(1): 1-11.

Hariyono K., J.M.M. Aji, R. Hartadi dan A. Supriono. 2014. Kajian Kesiapan Klaster dan Rancang Bangun Model Pemberdayaan Supply-Chain Agroindustri Intermediate Singkong Di Jawa Timur Sebagai Basis Industri Pangan Alternatif Nasional. Laporan Hasil Penelian. Penelitian MP3EI: Jember.

Misgiyarta, Syamsul, Mu'arif, Yandra, Arkenan. 2013. Strategi Teknologi dan Manajemen Inovasi Industri Tepung Kasava Fermentasi. Teknik Industri, 1(1): 64-78.

Nazir. 2003. Metode Penelitian. Bogor: Ghalia Indonesia.

Oladejo J.A. 2017. Marketing Efficiency Analysis Of Women Cassava Processors 
In Oyo State, Nigeria. Applied Science Reports, 19 (2): 62-66.

Prihantono, F.B. 2018. Analisis Pemasaran produk Agribisnis Ubi Kayu di Kabupaten Ponorogo Jawa Timur. Skripsi. Bogor: Departemen Agribinis Fakultas Ekonomi dan Manajemen IPB.

Rahman S. and Awerije B. 2014. Marketing efficiency of cassava products in Delta State, Nigeria: A stochastic profit frontier approach. Current Research Journal of Social Science 3(5). 1-32.

Riyad AJ. 2017. Analisis Pemasaran tepung Tapioka (Studi Kasus di Desa Ngemplak Kidul Kecamatan Margoyoso Kabupaten Pati). Skripsi. Semarang: Program Studi Agribisnis Fakultas Pertanian Universitas Wahid Hasyim.

Soekartawi. 1995. Analisis Usahatani. Jakarta: UI Press.

Soekartawi. 2002. Agribisnis: Teori dan Aplikasinya. Jakarta: Rajawali Pers.

Subandi. 2011. Deskripsi Kualitatif Sebagai Satu Metode dalam Penelitian Pertunjukan. HARMONIA, 11(2): 173-181.

Sudiyono, A. 2002. Pemasaran Pertanian. Malang: UMM Pers.

Sukesi, Heny. 2010. Kajian Rantai Pasokan dan Penganekaragaman Konsumsi Pangan Berbasis Produk Umbi-Umbian (Studi Kasus Jawa Barat). Buletin Ilmiah Litbang Perdagangan, 4(1): 31-65.

Sunarsi, S., M. Sugeng., S. Wahyuni, dan W. Ratnaningsih. 2011. Memanfaatkan Singkong Menjadi Tepung Mocaf Untuk Pemberdayaan Masyarakat Sumberejo. Pangan dan Agroindustri, 1(1): 306316.

Surya Y. P., Sri. Marwanti dan Kusnandar. 2016. Strategi Pengembangan Agroindustri Berbasis Ubi Kayu Di Kabupaten Wonogiri. Manajemen dan Bisnis, 3(1): 60-75.
Ugwumba C.O.A. and Onwuemeodo J.C. 2014. Fermented Cassava Flour Marketing in Owerri Metropolis of Imo State, Nigeria. Scholars Journal of Agriculture and Veterinary Sciences, 1 (2): 100-104.

Yulifianti R., Ginting E., dan Utomo JK. 2012. Tepung Kasava Modifikasi Sebagai Bahan Substitusi Terigu Mendukung Diversifikasi Pangan. Buletin Palawija No. 23: 1-12. 